\title{
Contact zones between chromosomal races of Mus musculus domesticus. 1. Temporal analysis of a hybrid zone between the CD chromosomal race $(2 n=22)$ and populations with the standard karyotype
}

\author{
RICCARDO CASTIGLIA* \& ERNESTO CAPANNA \\ Dipartimento di Biologia Animale e dell'Uomo, Università di Roma 'La Sapienza', \\ Via A. Borelli 50, 00161 Roma, Italy
}

\begin{abstract}
A temporal analysis of a hybrid zone between chromosomal races of Mus musculus domesticus was performed to evaluate its dynamics over a 20 -year period. The transect chosen was one previously analysed by Spirito et al. (1980) across the hybrid zone between the chromosomal race CD $2 n=22$ (central Italy) and the surrounding populations with standard karyotype $(2 n=40)$. The results show that 20 years of hybridization have not had any significant effect on the position of this hybrid zone, nor on the location of its extreme margin, except for one site for which passive transport of mice may have been important. The absence of a significant shift of the tension zone excludes a possible imbalance between the two cytotypes; a fitness superiority of one homozygote greater than 0.01 would have produced an appreciable shift of the zone. The internal chromosomal structure of the zone shows a constant gradual increase in metacentric chromosome frequency towards the localities nearest the area inhabited by the 22-CD homozygote population. This contrasts with the previously reported data which indicated an irregular trend, particularly evident for the $\mathrm{Rb}(3.8), \mathrm{Rb}(5.17)$ and $\mathrm{Rb}(6.13)$ chromosomes. For each $\mathrm{Rb}$ metacentric, we observed greater values of $F_{\mathrm{ST}}$ in the past sample than in the present one. These differences reveal a tendency towards the homogenization of adjacent populations, perhaps because of greater migration between adjacent demes resulting from increased commercial traffic. The Mantel test was performed for both temporal samples. A positive correlation between the geographical and chromosomal differentiation was demonstrated.
\end{abstract}

Keywords: hybrid zones, Mus musculus domesticus, Robertsonian races.

\section{Introduction}

The dynamics of hybrid zones and their evolutionary significance are topics of great interest (Barton \& Hewitt, 1985; Harrison, 1990). The notion that hybrid zones are ephemeral, leading to introgressive fusion or reinforcement, is based on the assumption that they are unstable (Harrison, 1990). By contrast, if hybrid individuals are better adapted to local ecological conditions, hybrid zones should be considered stable both spatially and temporally (Moore \& Buchanan, 1985). Moreover, mathematical models describing the dynamics of tension zones (hybrid zones that persist in time in dynamic equilibrium between selection against heterozygotes and

*Correspondence. E-mail: castiglia@axrma.uniroma1.it

(C) 1999 The Genetical Society of Great Britain. migration) allow the possibility of changes in their position and width (Barton, 1979; Barton \& Hewitt, 1985).

The best approach to test these different hypotheses is to perform direct long-term observations of hybrid zones. However, few such attempts have been made (Harrison, 1990 for a review). With few exceptions, all the temporal analyses concentrate on the morphological characters of the hybridizing taxa, owing to the scarcity of genetic data in the literature. In fact, only taxa with a long history of genetic studies can be used (Polyakov et al., 1997). One of these is the house mouse Mus musculus domesticus, which has been the subject of cytogenetic studies since the 1960s (Gropp et al., 1969; Capanna et al., 1976); its high chromosomal variability leads to a large number of chromosomal races with a diploid number ranging from $2 n=40$, all telocentric 
chromosomes, to $2 n=22$ with nine Robertsonian ( $\mathrm{Rb}$ ) fusions.

We re-analysed an $18-\mathrm{km}$ transect, located in central Italy, crossing the hybrid zone between the chromosomal race $\mathrm{CD} 2 n=22$ and the surrounding populations with standard karyotype $(2 n=40)$ of $M . m$. domesticus. This transect was previously examined by Spirito et al. (1980) using a cytogenetic approach. Their study was based on about 40 animals collected in 1976 (M. Cristaldi, pers. comm.). Hoechst 33258 staining allowed identification of the chromosomal arms of $\mathrm{Rb}$ metacentrics for 20 animals only. Sampling for the present study was carried out between December 1996 and April 1998. Therefore, more than 20 years had elapsed since the analysis by Spirito et al. (1980). This period of time in the house mouse, in a temperate Mediterranean region, corresponds to around one hundred generations because of its continuous reproductive activity and precocious sexual maturity. We have found pregnant or lactating females from March to November and, according to the data of Berry (1981) and Pelikán (1981), this means four or five generations per year.

This new analysis is interesting because it can provide evidence of some factors affecting the dynamics of the hybrid zone. The supposed selective superiority of the chromosomal rearrangements (Sage et al., 1993) could be verified if we were to reveal a shift in the position of the zone. The importance of the commensalism with man, which promotes intense passive transport, can be seen by the evidence of long-distance spread of mice characterized by different cytotypes. We will be able to detect any temporal changes in the chromosomal structure of the populations, and a comparison between the features of the area presently investigated and that of an adjacent transect of the same hybrid zone (Corti \& Ciabatti, 1988), with different geographical and human activity patterns, will elucidate the role played by geographical factors in the process.

We have planned an extensive analysis of this hybrid zone which will comprise all aspects related to the fertility of the hybrids and the efficiency of the hybrid zone as a barrier to genetic and chromosomal flow, as well as a careful analysis of the genetic and chromosomal structure of each deme. In this paper we report on the evaluation of the changes that have occurred in the hybrid zone after 20 years.

\section{Materials and methods}

Seventy-five animals were trapped between 1996 and 1998 along the transect in 10 localities between 1.3 and $4.4 \mathrm{~km}$ apart (Fig. 1 and Table 1). The distance between localities was measured along the valley road that connects them. Six localities are the same as those

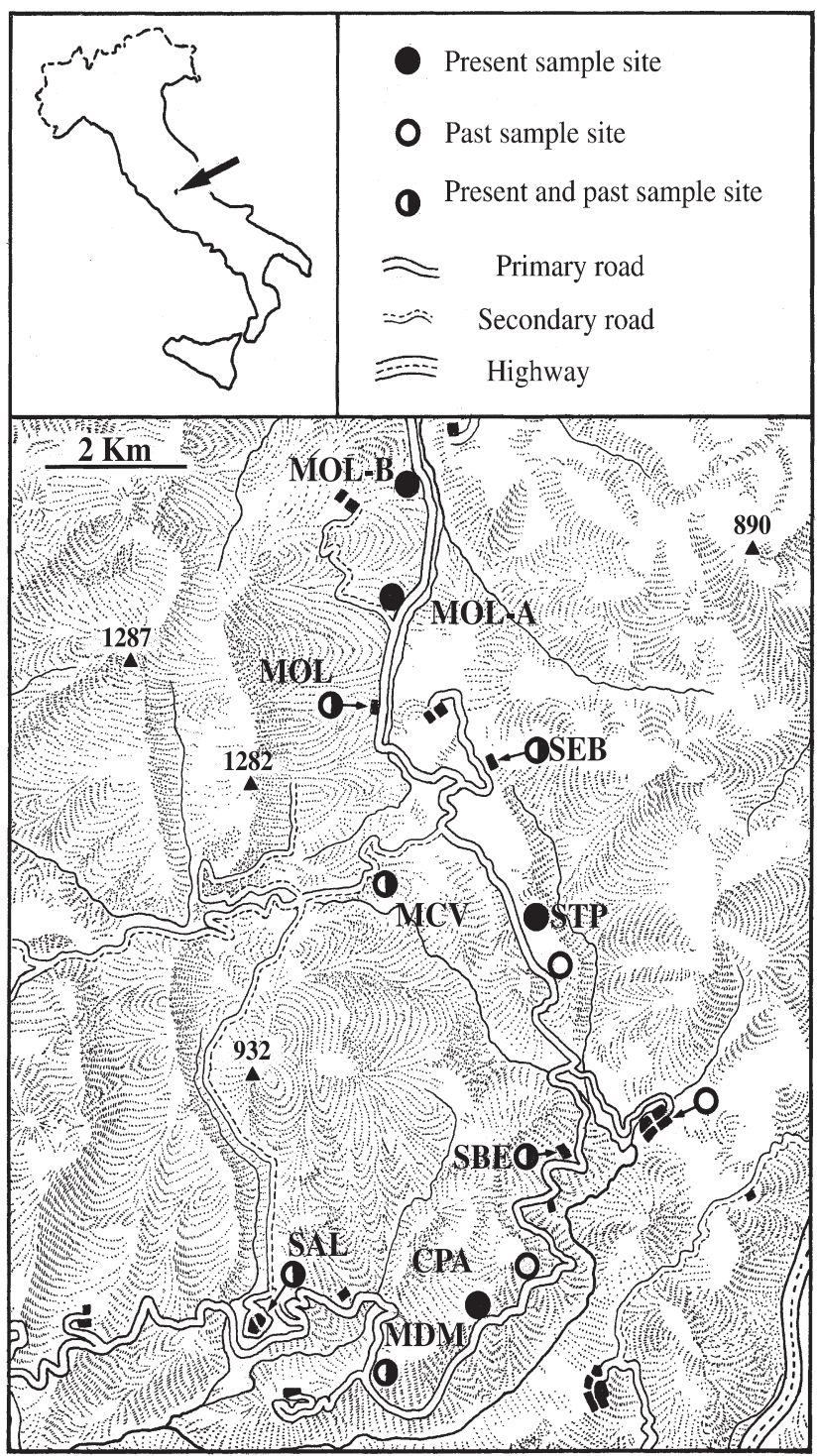

Fig. 1 Location of sample sites along the Sabina transect.

studied by Spirito et al. (1980): Salisano (SAL), Madonna del Mattone (MDM), San Benedetto (SBE), Montecavallo (MCV), San Sebastiano (SEB; called Monte San Giovanni in Spirito et al., 1980) and Le Mole (MOL). At the Colle Paradiso (CPA) and Santo Pietro (STP) villages, the animals were collected $1 \mathrm{~km}$ and $400 \mathrm{~m}$, respectively, from the sites of the previous sample (see Fig. 1). Animals were also trapped at two new sites near Le Mole at the end of the transect in the area of the homozygous 22 chromosome population (Mole-A and Mole-B).

Karyotype analyses were performed on somatic metaphase plates from both bone marrow preparations, following the standard air-drying procedure suggested by Hsu \& Patton (1969), and cultured cells from ear

(c) The Genetical Society of Great Britain, Heredity, 83, 319-326. 
Table 1 Sample site, sample size, location, mean diploid chromosome number, mean structural heterozygosity (Ko), number of heterozygous chromosomes per individual (mean value and range) and frequencies of metacentric chromosomes in the sample sites along the transect of house mice (see also Fig. 1)

\begin{tabular}{|c|c|c|c|c|c|c|c|c|c|c|c|c|c|c|}
\hline \multirow[b]{2}{*}{ Site } & \multirow[b]{2}{*}{$N$} & \multirow{2}{*}{$\begin{array}{l}\mathrm{Km} \\
\text { from } \\
\text { SAL }\end{array}$} & \multirow{2}{*}{$\begin{array}{c}2 n \\
\text { (mean) }\end{array}$} & \multirow[b]{2}{*}{ Ko } & \multirow{2}{*}{$\begin{array}{l}\text { Mean number of het. } \\
\text { chromosomes per } \\
\text { individual (min-max) }\end{array}$} & \multicolumn{9}{|c|}{ Freq. of metacentric chromosomes } \\
\hline & & & & & & 1.7 & 2.18 & 3.8 & 4.15 & 5.17 & 6.13 & 10.11 & 9.16 & 12.14 \\
\hline SAL & 6 & 0 & 37.5 & 0.24 & $2.17(2-3)$ & 0 & 0 & 0 & 0.08 & 0.42 & 0 & 0 & 0.5 & 0.25 \\
\hline MDM & 16 & 1.3 & 39.8 & 0.02 & $0.19(0-1)$ & 0.03 & 0 & 0 & 0 & 0 & 0 & 0.03 & 0.03 & 0 \\
\hline CPA & 15 & 2.9 & 38.8 & 0.07 & $0.67(0-2)$ & 0.1 & 0 & 0 & 0 & 0.07 & 0.33 & 0 & 0.1 & 0 \\
\hline SBE & 12 & 5.6 & 35 & 0.39 & $3.5 \quad(0-7)$ & 0.29 & 0.17 & 0.42 & 0.21 & 0.42 & 0.21 & 0.08 & 0.46 & 0.25 \\
\hline STP & 7 & 10 & 26.3 & 0.32 & $2.86(1-5)$ & 0.79 & 0.71 & 1 & 0.93 & 0.57 & 0.93 & 0.57 & 1 & 0.36 \\
\hline MCV & 4 & 11.3 & 24.75 & 0.14 & $1.25(0-2)$ & 1 & 0.87 & 1 & 0.75 & 0.75 & 0.75 & 1 & 1 & 0.5 \\
\hline SEB & 1 & 12.6 & 22 & 0 & 0 & 1 & 1 & 1 & 1 & 1 & 1 & 1 & 1 & 1 \\
\hline MOL & 2 & 14.3 & 22.5 & 0.05 & $0.5 \quad(0-1)$ & 1 & 1 & 0.75 & 1 & 1 & 1 & 1 & 1 & 1 \\
\hline MOL-A & 4 & 16.3 & 22 & 0 & 0 & 1 & 1 & 1 & 1 & 1 & 1 & 1 & 1 & 1 \\
\hline MOL-B & 8 & 18.3 & 22 & 0 & 0 & 1 & 1 & 1 & 1 & 1 & 1 & 1 & 1 & 1 \\
\hline Total & 75 & & & & & & & & & & & & & \\
\hline
\end{tabular}

biopsy (Stanyon \& Galleni, 1991). G-bands induced according to Seabright's routine (1971) allowed a correct assessment of the Rb metacentrics. An unbiased estimate of the $P$-value of Fisher's exact test was computed with the GENEPOP 3.1 B program, an updated version of GENEPOP 1.2 described in Raymond \& Rousset (1995), to detect any temporal differences in the chromosomal frequencies in those polymorphic populations for which direct comparison was possible: Salisano, Madonna del Mattone, San Benedetto and Montecavallo. To test for population differentiation between the spatially and temporally separated samples, we calculated $F_{\text {ST }}$ values using the GENETIX 3.3 program (Belkhir et al., 1996-98) and the $P$-value for $F_{\mathrm{ST}}>0$ according to Weir \& Cockerham (1984). The significance of the $F_{\mathrm{ST}}$ values was tested using 5000 permutations. The Mantel test (Mantel, 1967) was performed for the present and past samples to test the isolation by distance model with the program ISOLDE of the GENEPOP package (Raymond \& Rousset, 1995) using 10000 permutations. As input for the two matrices we used pairwise $F_{\mathrm{ST}}$ values and geographical distances. Relationships were plotted according to Slatkin (1993) as $\log _{10}(M)=\left(1 / F_{\mathrm{ST}}-1\right) / 4$ against $\log _{10}$ distance $(d)$.

\section{Results}

Table 1 shows the locality, the number of specimens studied, the mean diploid number, the average structural heterozygosity $(\mathrm{Ko})$, the mean number of heterozygous chromosomes per individual and the frequencies of each metacentric chromosome for each locality. The same data have been inferred from the paper of Spirito et al.
(1980) and partly compared with the present data in Figs 2 and 3. The graph showing the mean diploid chromosome numbers (Fig. 2a) indicates a close correspondence between the two sets of data. For the average heterozygosity in the population (Fig. 2b), the comparison shows the same pattern of variation in the two samples: higher in the centre of the transect than at the extremities. In both samples, the maximum values were found in the village of San Benedetto. These values are very similar, i.e. $K o=0.37$ in 1976 and $K o=0.39$ in the current sample. Minor variations were found in both diploid number and structural heterozygosity at a local level. The mean number of chromosomes in the heterozygous condition per individual is high in the populations at the centre of the transect, i.e. SBE (mean 3.5) and STP (mean 2.9) in which extreme individuals were found with seven and five chromosomes in heterozygosity, respectively. Spirito et al. (1980) found similar mean values but the maximum number of metacentrics in the heterozygous condition was four in the SBE population. The approximate cline width of the zone can be estimated using the definition of Barton \& Gale (1993) (inverse of maximum slope) on a graph plotting the average frequencies of the $\mathrm{Rb}$ metacentrics in each population against the distances along the transect. The graph (Fig. 2c) representing the past and present situations shows a close correspondence, with a width equal to $9100 \mathrm{~m}$.

In spite of the correspondence in diploid numbers, the chromosomal structure of the zone, as revealed by the frequencies of each $\mathrm{Rb}$ fusion, appear to have changed (Fig. 3). In the present sample, the trends of the frequencies of the metacentrics show a constant gradual 

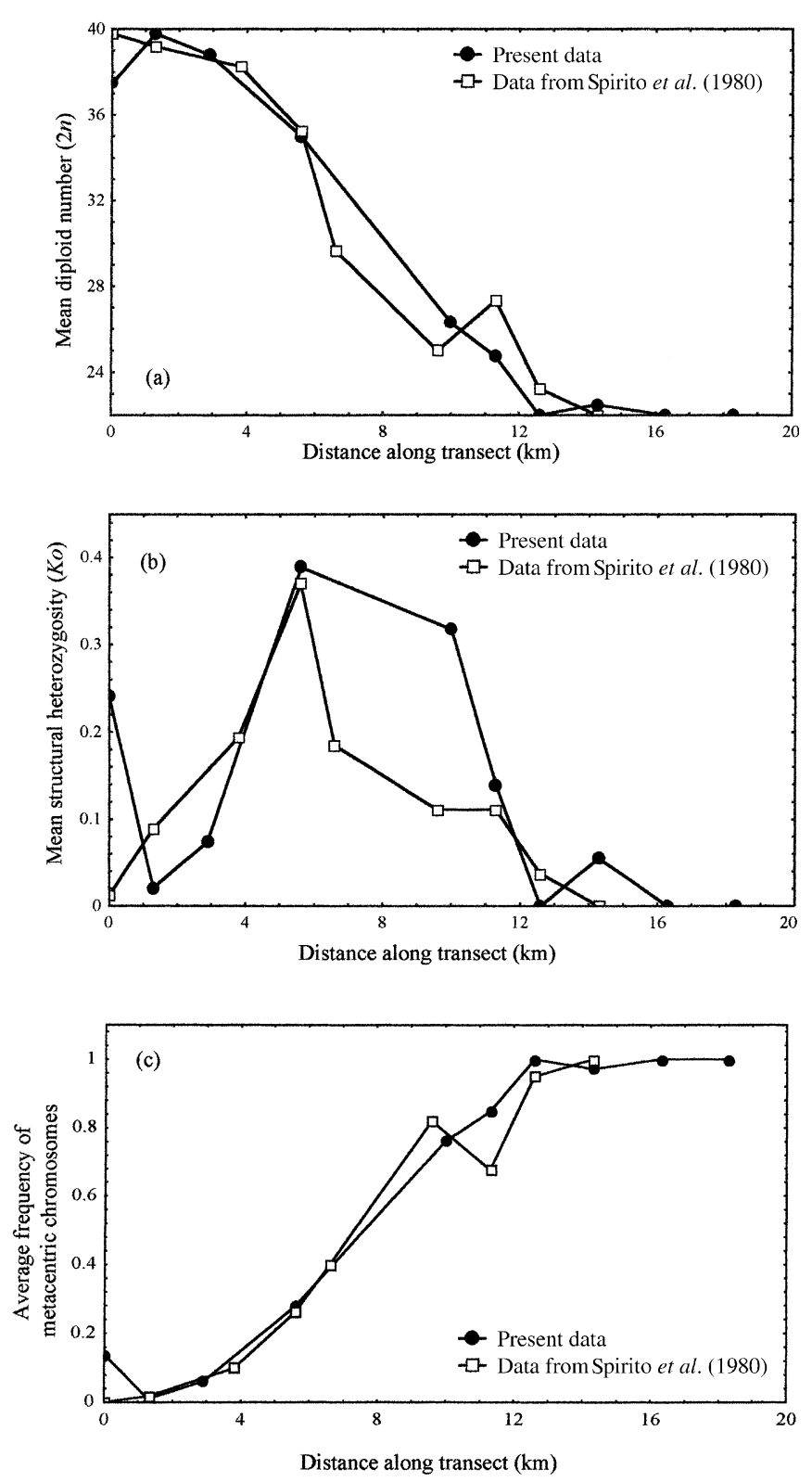

Fig. 2 The variation in (a) mean diploid chromosome number $(2 n)$, (b) mean structural heterozygosity $(\mathrm{Ko})$ and (c) average frequency of metacentrics in house mice along the transect, according to Spirito et al. (1980) ( $\square$ ) and the present observations $(-)$. The distance between localities was measured along the valley road that connects them.

increase towards the locality nearest the area inhabited by the 22-CD homozygote population. These findings contrast with the previously reported data (Spirito et al., 1980) which indicated an irregular trend for the distribution of chromosomal frequency even in nearby populations.

This is evident for $\mathrm{Rb}(3.8), \mathrm{Rb}(5.17)$ and $\mathrm{Rb}(6.13)$. Significant differences in the chromosomal frequencies of two of these chromosomes have been detected in two populations: in Montecavallo $\mathrm{Rb}(3.8)$ is now present (Fisher's exact test, $P=0.002$ ) (double arrow in Fig. 3c) and in San Benedetto the frequency of $\mathrm{Rb}(6.13)$ has decreased (Fisher's exact test $P=0.009$ ) (double arrow in Fig. 3f).

Other differences emerged from a comparison of the chromosomal frequencies (Fisher exact test). In Salisano four different metacentrics are now present, i.e. $\mathrm{Rb}$ (4.15), $\mathrm{Rb}$ (5.17), $\mathrm{Rb}(9.16), \mathrm{Rb}(12.14)$, whereas only one (not identified) was found with a low frequency in the previous sample. The frequencies are statistically different for $\mathrm{Rb}(5.17) \quad(P=0.007)$ and $\mathrm{Rb}(9.16)$ $(P=0.002)$ (double arrows in Fig. 3e,g).

Figure 3(h) shows a clinal trend of two Robertsonian metacentrics, i.e. $\mathrm{Rb}$ (10.11) and $\mathrm{Rb}$ (12.14), which were not distinguished by Spirito et al. (1980) because of the low definition of the banding pattern obtained by the Hoechst method.

We computed the interlocality karyotypic heterogeneity $\left(F_{\mathrm{ST}}\right)$ as a measure of the among-subdivision variance in chromosomal frequencies. Overall $F_{\mathrm{ST}}$ (Table 2) values calculated for each $\mathrm{Rb}$ metacentric for all polymorphic populations were very high in both samples, indicating strong differentiation between subpopulations. In the present sample, the $F_{\mathrm{ST}}$ values range from 0.22 to 0.78 , all values being significantly greater than zero $(P<0.001)$. For all $\mathrm{Rb}$ metacentrics, $F_{\mathrm{ST}}=0.55(P<0.001)$. For the Spirito et al. (1980) sample, the $F_{\mathrm{ST}}$ values are higher for each metacentric (range 0.67-0.94), all values being significantly greater than zero $(P<0.001)$. Overall $F_{\mathrm{ST}}=0.80(P<0.001)$. These values demonstrate that the populations were more differentiated in the earlier sample than in the present one. A lower level of migration between localities in the past might account for this pattern. Chromosomal differences between the temporal samples were found to be significant (pairwise $F_{\mathrm{ST}}$ values) in Salisano $\quad F_{\mathrm{ST}}=0.44 \quad(P<0.01), \quad$ San Benedetto $F_{\mathrm{ST}}=0.17 \quad(P<0.02)$ and Montecavallo $F_{\mathrm{ST}}=0.48$ $(P<0.01)$. The Mantel test performed for both temporal samples revealed a positive correlation between the geographical and chromosomal differentiation. The probability of the association being random was, respectively, 0.017 and 0.0005 . Pairwise values related to the present (circles) and the past samples (squares) are plotted in Fig. 4.

\section{Discussion}

Our results show that 20 years of hybridization have not had significant effects on the position of this hybrid zone, nor on the location of its extreme margin. Thus the hybrid zone does not change its position or width 

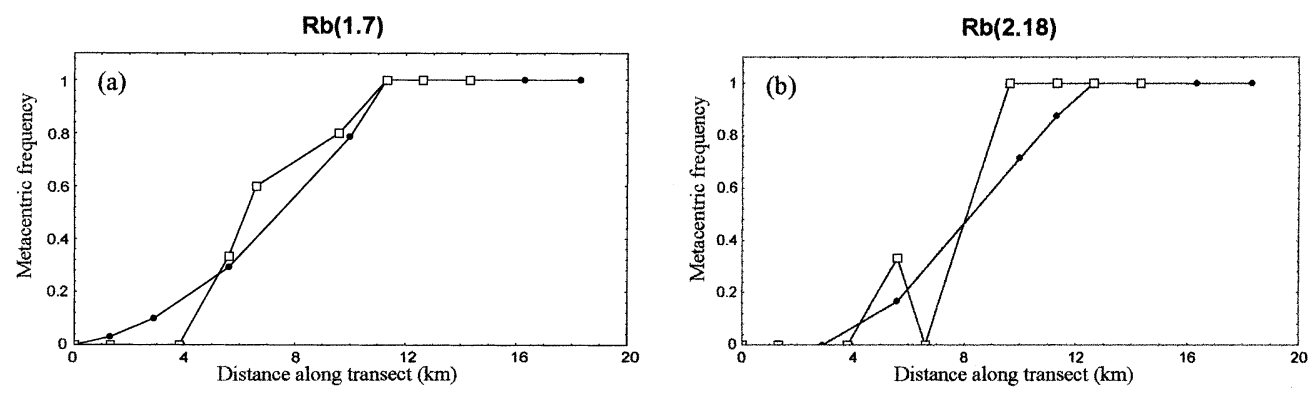

$\mathrm{Rb}(3.8)$

$\mathbf{R b}(4.15)$
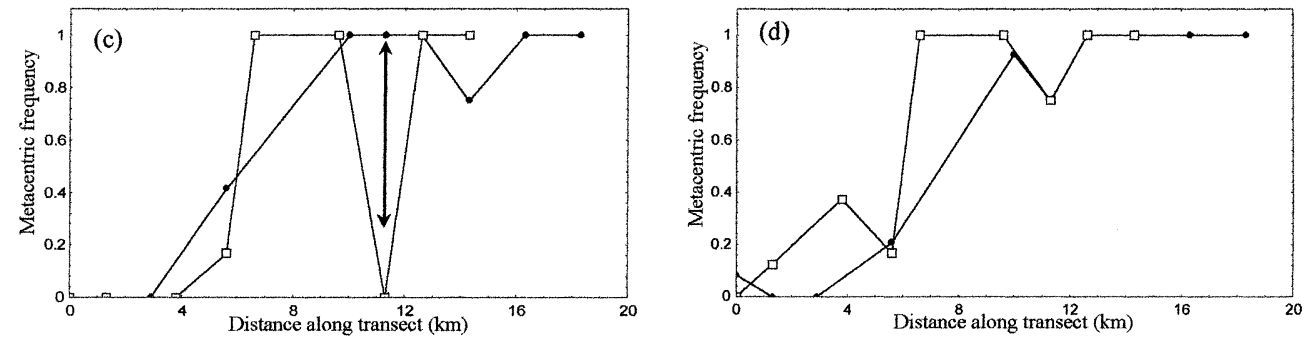

$\mathrm{Rb}(5.17)$
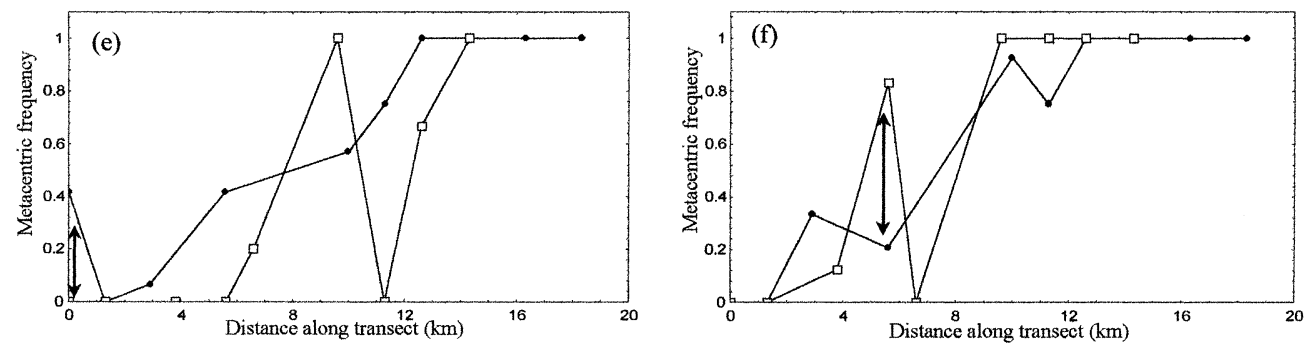

$\mathrm{Rb}(9.16)$
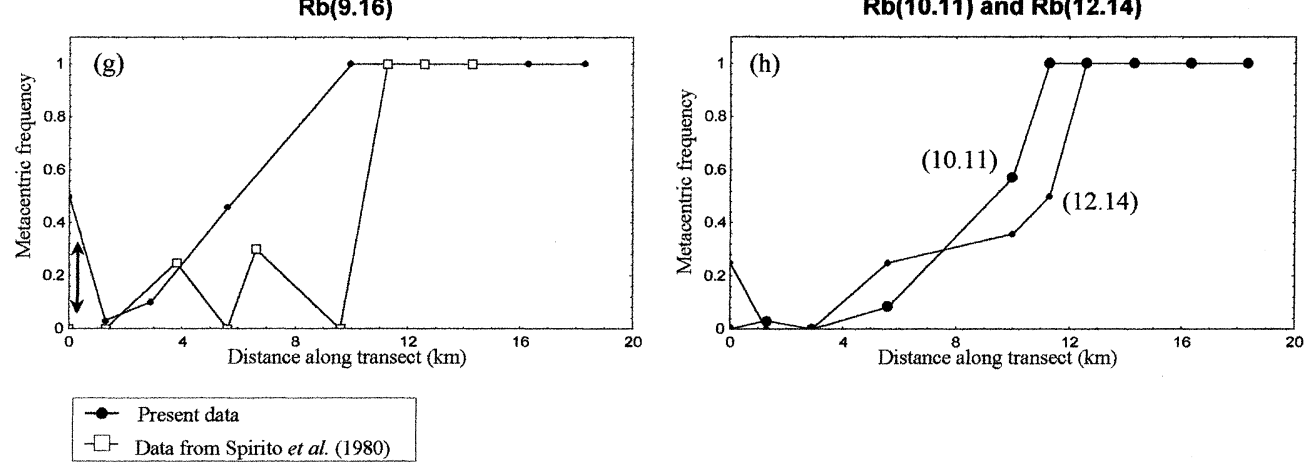

Fig. 3 (a-g) The variation in metacentric frequencies across the house mouse hybrid zone transect in 1976 ( $\square$ ) and in $1997-98$ (h) The variation in the frequencies of $\mathrm{Rb}(10.11)$ and $\mathrm{Rb}(12.14)$ in the present sample. The distance between localities was measured along the valley road that connects them. Double arrows indicate significant differences in frequencies between the two temporal samples.

rapidly. Nonetheless, the consistent presence of metacentric chromosomes in Salisano, described by Spirito et al. (1980) as a border deme with standard karyotype (only one $2 n=39$, out of nine mice, was found) could be considered of some interest. It may be the result of a recent passive introgression. Indeed the animals in this site were trapped in an olive oil mill where numerous trucks stop during the olive harvest period. Mice could thus easily be transported from neighbouring areas. This hypothesis is supported by the high structural heterozygosity $(K o=0.24)$ and by the high number of metacentrics in heterozygosity (range $2-3$ ) in SAL with respect to the marginal position of this sample on the transect. These characters can be considered as arising from crossings of local all-telocentric mice with mice bearing metacentric chromosomes in homozygosity. 
Table 2 Interdeme karyotype heterogeneity $\left(F_{\mathrm{ST}}\right)$ of house mice for each $\mathrm{Rb}$ metacentric and for all the metacentrics computed for the present data and for the data of Spirito et al. (1980)

\begin{tabular}{lcc}
\hline Metacentric & $\begin{array}{c}F_{\text {ST }} \\
\text { Present data }\end{array}$ & $\begin{array}{c}F_{\text {ST }} \\
\text { Spirito } \text { et al. (1980) }\end{array}$ \\
\hline $\mathrm{Rb}(1.7)$ & 0.541 & 0.701 \\
$\mathrm{Rb}(2.18)$ & 0.630 & 0.903 \\
$\mathrm{Rb}(3.8)$ & 0.779 & 0.944 \\
$\mathrm{Rb}(4.15)$ & 0.658 & 0.733 \\
$\mathrm{Rb}(5.17)$ & 0.342 & 0.672 \\
$\mathrm{Rb}(6.13)$ & 0.495 & 0.883 \\
$\mathrm{Rb}(10.11)$ & 0.639 & - \\
$\mathrm{Rb}(9.16)$ & 0.575 & 0.691 \\
$\mathrm{Rb}(12.14)$ & 0.223 & - \\
$\mathrm{All} \mathrm{Rb}$ & 0.553 & 0.798 \\
\hline
\end{tabular}

We found animals with high chromosomal heterozygosity in the locality at the centre of the transect; the maximum number observed was seven (found in SBE). Because such high heterozygosity has a detrimental effect on fertility (for reviews see Redi \& Capanna, 1988 and Hauffe \& Searle, 1998), we assume that these chromosomal clines are maintained by a selectiondispersal balance (Barton \& Hewitt, 1985). The first step is to verify the supposed selective imbalance between the two homozygote chromosomal races. Barton (1979) suggested a mathematical model showing that a tension zone, involving a single-locus cline, can move in response to a selective imbalance between the two homozygotes. The speed of the movement is $(S / 2) \sqrt{ } 2 m / \sqrt{ } s)$, where $2 S$ is the superiority of one homozygote over the other and

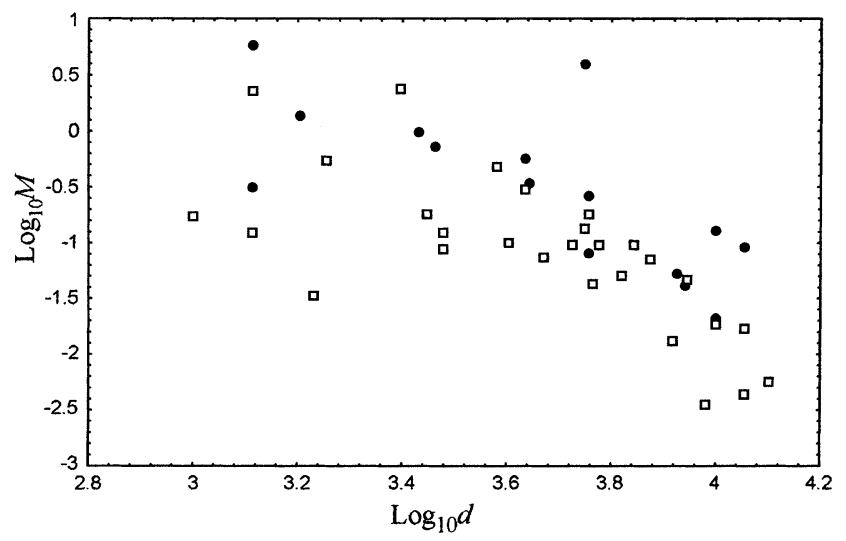

Fig. 4 Pairwise $F_{\mathrm{ST}}$ values for karyotypic heterogeneity in house mice and distance between sample sites: present data ( and data from Spirito et al., 1980 ( $\square$ ). Relationships were plotted according to Slatkin (1993) as $\log _{10}(M)=\left(1 / F_{\mathrm{ST}}-1\right) / 4$ against $\log _{10}$ distance $(d)$.
Table 3 Expected speed of the zone as a result of the action of different values of selective superiority $(2 S)$ of one homozygote over the other, according to the model of Barton (1979) (see text)

Homozygote superiority

2S (Barton, 1979)

Expected speed (m/gen.)

\begin{tabular}{lc}
\hline 0.01 & 22.75 \\
0.02 & 45.5 \\
0.04 & 91 \\
0.08 & 182 \\
\hline
\end{tabular}

$\sqrt{ } 2 m / \sqrt{ } s$ is the width (w) of the zone in a tension zone model, $m$ being the variance in progeny position per generation and $s$ the fitness deficit for the hybrid. With the width of the zone assumed to be $9100 \mathrm{~m}$, Table 3 shows, for different values of $2 S$, the expected shift per generation of the zone according to the Barton (1979) model. A selective imbalance between the two homozygotes produces a sensible shift of the zone, into the less fit race. For values of $2 S$ between 0.01 and 0.02 , the estimated shift over 100 generations is between 2275 and $4550 \mathrm{~m}$, respectively. For higher values of $2 S(0.04$ and $0.08)$ the shift becomes quite marked $(9100 \mathrm{~m}$ and $18200 \mathrm{~m}$, respectively). Therefore the positional stability of this transect does not agree with the hypothesis of a selective superiority of one chromosomal race over the other, at least in the range of the selective disadvantage values used in this analysis.

However, the position of hybrid zones can be maintained if different parental types are favoured in different ecological conditions (Howard \& Warings, 1991). The area of hybridization we analysed is situated on the border between the Apennine zone (mesophilic) and the alluvial plain of the Tiber River (thermoxerophilic) (Tomaselli et al., 1973). Ecological constraints could thus contribute to the separation of the two chromosomal races, as has been hypothesized for other hybridization areas of M. m. domesticus (Corti \& Thorpe, 1989; Said \& Britton-Davidian, 1991; Searle et al., 1993). In support of this view, significant differences have been found in litter size between the $C D$ race and the standard one (mean litter size $\mathrm{CD}=6.2$, standard $=4.5$; see Castiglia, unpubl. obs.). This difference in reproductive output may represent a different demographic strategy related to the habitat segregation (Said et al., 1993).

Capanna \& Redi (1994) suggested a model in which the chromosomal configuration can be a selective factor. It is based on the possibility that $\mathrm{Rb}$ fusion can alter the spatial organization of the interphase nucleus, changing the gene cluster locations into nuclear domains programmed for regulatory functions. Hence the different expression of the genes could affect relative fitnesses under different environmental conditions. 
The spatial stability we detected in this hybrid zone might also be explained by the tension zone model, which shows how natural barriers or regions of low population density can trap tension zones (Barton, 1979). In this area, no true geographical barriers are present, although human settlements can play a role in spacing the microdemes of mice that are commensal with man. Villages, or small groups of houses, are present in a continuous pattern throughout the transect, although a thinning of buildings can be observed between San Benedetto and Santo Pietro (Fig. 1). The Mantel test showed a significant correlation between interdeme distance and pairwise $F_{\mathrm{ST}}$ values in both temporal samples. Hence the greater distances between human settlements in the centre of the transect than at the margins can influence (i.e. lessen) the migration between populations, acting as a partial barrier to genetic flow. In this regard, it is important to underline the geographical character of this transect: all the human activities are concentrated along this single valley route and it determines the pattern of spreading of the mouse populations. An alternative route between SAL and MCV exists (Fig. 1) but it runs through mountain forests and lacks stable human settlements. Consequently it is not suitable for house mouse populations.

Corti \& Ciabatti (1988) found no evidence of clinal variation in diploid chromosome number nor in the frequencies of any one $\mathrm{Rb}$ metacentric in another transect in the same hybrid zone located $60 \mathrm{~km}$ north of the area investigated by us. The geographical characters of the two transects are quite different, which can account for the different chromosomal structures. The transect studied by Corti \& Ciabatti (1988) is located in a hilly, intensively cultivated area crossed by a network of country roads. Consequently the hybrid zone assumes a greater width and an unorientated structure as far as the distribution of the diploid number is concerned. A thorough analysis of the chromosomal structure of the two areas is in progress and will be presented in a further paper.

Although the hybrid zone was found to be stable, the chromosomal structure of its populations has been altered, leading to a smoother gradient in $\mathrm{Rb}$ frequency change than previously observed. This change is marked by significant differences in chromosomal frequencies and in pairwise $F_{\mathrm{ST}}$ values (significantly $>0$ ) in three of the four localities for which direct comparison was possible. We observed greater values of $F_{\mathrm{ST}}$ for each $\mathrm{Rb}$ metacentric in the earlier sample than in the present one. These differences reveal a homogenizing of adjacent populations. Nonetheless, the underlying reason for this pattern is not easy to explain. A break in the local isolation could have occurred as a result of increasing migration between adjacent populations, caused by increases in commercial traffic or by recent improvements of the mountain agriculture in this district.

The present study has demonstrated the stability of this hybrid zone, at least over the short term. Several factors can account for this stability: the action of a partial barrier to genetic flow, represented by the central area of the transect where the populations are more spaced out; an absence of selective differences between the two different cytotypes; and adaptation to the different ecological conditions by the parental populations. Nevertheless, the spatial stability of a hybrid zone is not unequivocal evidence in support of a given hypothesis, as was stated by Moore \& Buchanan (1985). In fact, 20 years of hybridization may not be long enough for slow movement of this hybrid zone. However, we demonstrate that within the hypothesized values, a selective imbalance between the two races would be revealed. The changes we observed in the internal structure of the demes of the hybrid zone, concerning chromosomal frequencies and $F_{\mathrm{ST}}$ values, can been explained in terms of a decrease of interdeme isolation and/or a more careful data analysis performed on a larger sample than that of Spirito et al. (1980). Fertility estimates and analysis of gene flow are presently in progress, in order to evaluate selection against heterozygotes and to investigate some aspects of this tension zone model.

\section{Acknowledgements}

We are grateful to Mauro Cristaldi and Maria Vittoria Civitelli for their helpful suggestions. Thanks are extended to Giuseppe Gentili and Angela Durante for performing the cell cultures. Marco Caporioni and Alessandra Scanzani provided aid in the field.

\section{References}

BARTON, N. H. 1979. The dynamics of hybrid zones. Heredity, 43, 341-359.

BARTON, N. H. AND GALE, K. S. 1993. Genetic analysis of hybrid zones. In: Harrison, R. G. (ed.) Hybrid Zones and the Evolutionary Process, pp. 13-45. Oxford University Press, New York.

BARTON, N. H. AND HEWITT, G. M. 1985. Analysis of hybrid zones. Ann. Rev. Ecol. Syst., 16, 113-148.

BELKHIR, K., BORSA, P., GOUDET, J., CHIKHI, L. AND BONHOMME, F. 1996-98. GENETIX, logiciel sous Windows TM pour la génétique des populations. Laboratoire Génome et Populations, CNRS UPR 9060, Université de Montpellier II, Montpellier, France.

BERRY, R. J. 1981. Population dynamics of the house mouse. Symp. Zool. Soc. Lond., 47, 395-425.

CAPANNA, E. AND REDI, C. A. 1994. Chromosomes and the microevolutionary processes. Boll. Zool., 61, 285-294. 
CAPANNA, E., GROPP, A., WINKING, G., NOACK, G. AND CIVITELLI, M. V. 1976. Robertsonian metacentrics in the mouse. Chromosoma, 58, 341-353.

CORTI, M. AND CIABATTI, C. M. 1988. The structure of a chromosomal hybrid zone of house mice (Mus domesticus) in central Italy: cytogenetic analysis. Z. Zool. Syst. Evol.Forsch., 28, 277-288.

CORTI, M. AND THORPE, R. S. 1989. Morphological clines across a karyotypic zone of house mice in central Italy. J. Evol. Biol., 2, 253-254.

GROPP, A., TETTENBORN, U. AND VON LEHMANN, E. 1969. Chromosomenuntersuchungen bei der Tabakmaus (M. poschiavinus) und bei den Hybriden mit der Laboratorumsmaus. Experientia, 25, 875-876.

HARRISON, R. G. 1990. Hybrid zones: windows on the evolutionary process. Oxford Surv. Evol. Biol., 7, 69-128.

HAUFFE, H. C. AND SEARLE, J. B. 1998. Chromosomal heterozygosity and fertility in house mice (Mus musculus domesticus) from Northern Italy. Genetics, 150, 1143-1154.

HOWARD, D. J. AND WARINGS, G. L. 1991. Topographic diversity, zone width, and the strength of reproductive isolation in a zone of overlap and hybridization. Evolution, 45, 1120-1135.

HSU, T. C. AND PATTON, J. L. 1969. Bone marrow preparations for chromosome studies. In: Benirschke, K. (ed.) Comparative Mammalian Cytogenetics, pp. 454-460. Springer, Berlin.

MANTEL, N. 1967. The detection of disease clustering and a generalized regression approach. Cancer Res., 27, 209-220.

MOORE, w. S. AND BUCHANAN, D. B. 1985. Stability of the northern flicker hybrid zone in historical times: implications for adaptive speciation theory. Evolution, 39, 135-151.

PELIKÁN, J. 1981. Pattern of reproduction in the house mouse. Symp. Zool. Soc. Lond., 47, 205-229.

POLYAKOV, A. V., CHADOVA, N. B., RODIONOVA, M. I., PANOV, V. V., DOBROTVORSKY, A. K., SEARLE, J. B. AND BORODIN, P. M. 1997. Novosibirsk revisited 24 years on: chromosome polymorphism in the Novosibirsk population of the common shrew Sorex araneus L. Heredity, 79, 172-177.
RAYMOND, M. AND ROUSSET, F. 1995. GENEPOP (Version 1.2): population genetics software for exact tests and ecumenicism. J. Hered., 86, 248-249.

REDI, C. A. AND CAPANNA, E. 1988. Robertsonian heterozygotes in the house mouse and the fate of their germ cells. In: Daniel, A. (ed.) The Cytogenetics of Mammalian Autosomal Rearrangements, pp. 315-359. Alan R. Liss, New York.

SAGE, R. D., ATCHLEY, W. R. AND CAPANNA, E. 1993. House mice as models in systematic biology. Syst. Biol., 42, 523-561.

SAID, K. AND BRITTON-DAVIDIAN, J. 1991. Genetic differentiation and habitat partition of Robertsonian house mouse populations (Mus musculus domesticus) of Tunisia. J. Evol. Biol., 3, 409-427.

SAID, K., SAAD, A., AUFFRAY, J.-C. AND BRITTON-DAVIDIAN, J. 1993. Fertility estimates in the Tunisian all-acrocentric and Robertsonian populations of the house mouse and their chromosomal hybrids. Heredity, 71, 532-538.

SEABRIGHT, M. A. 1971. A rapid banding technique for human chromosomes. Lancet, 2, 971-972.

SEARle, J. B., NAVARRo, Y. N. AND GANEM, G. 1993. Further studies of a staggered hybrid zone in Mus musculus domesticus. Heredity, 71, 523-531.

SLATKIN, M. 1993. Isolation by distance in equilibrium and non-equilibrium populations. Evolution, 35, 477-488.

SPIRITO, F., MODESTI, A., PERTICONE, P., CRISTALDI, M., FEDERICI, R. AND RIZZONI, M. 1980. Mechanisms of fixation and accumulation of centric fusions in natural populations of Mus musculus L. I. Karyological analysis of an hybrid zone between two populations in the central Apennines. Evolution, 34, 453-466.

STANYON, R. AND GALLENI, L. 1991. A rapid fibroblast culture technique for high resolution karyotypes. Boll. Zool., 58, 81-83.

TOMASElli, R., BALDUZZI, A. AND FILIPELlo, S. 1973. Carta Bioclimatica D'italia. Ministero Agricoltura e Foreste, Roma.

WEIR, B. S. AND COCKERHAM, C. C. 1984. Estimating $F$-statistics for the analysis of population structure. Evolution, 38, 13581370 . 